AperTO - Archivio Istituzionale Open Access dell'Università di Torino

\title{
Differences in the climate debts of birds and butterflies at a continental scale
}

\section{This is the author's manuscript}

Original Citation:

Availability:

This version is available http://hdl.handle.net/2318/123058

since

Published version:

DOI:10.1038/nclimate1347

Terms of use:

Open Access

Anyone can freely access the full text of works made available as "Open Access". Works made available under a Creative Commons license can be used according to the terms and conditions of said license. Use of all other works requires consent of the right holder (author or publisher) if not exempted from copyright protection by the applicable law. 


\section{(2) \\ UNIVERSITÀ DEGLI STUDI DI TORINO}

This is an author version of the contribution published on:

Questa è la versione dell'autore dell'opera:

Nature Climate Change, 2: 121-124, 2012, 10.1038/nclimate1347

The definitive version is available at:

La versione definitiva è disponibile alla URL:

http://www.nature.com/nclimate/journal/v2/n2/full/nclimate1347.html 


\section{Differences in the climatic debts of birds and butterflies at a continental scale}

Vincent Devictor $^{1 *}$, Chris van Swaay ${ }^{2}$, Tom Brereton ${ }^{3}$, Lluís Brotons ${ }^{4,5}$, Dan

Chamberlain $^{6}$, Janne Heliölä ${ }^{7}$, Sergi Herrando ${ }^{4}$, Romain Julliard ${ }^{8}$, Mikko Kuussaari ${ }^{7}$, Åke Lindström ${ }^{9}$, Jiří Reif ${ }^{10}$, David B. Roy ${ }^{11}$, Oliver Schweiger ${ }^{12}$, Josef Settele ${ }^{12}$, Constantí Stefanescu ${ }^{13}$, Arco Van Strien ${ }^{14}$, Chris Van Turnhout ${ }^{15,16}$, Zdeněk Vermouzek $^{17}$, Michiel WallisDeVries ${ }^{2,18}$, Irma Wynhoff ${ }^{2}$, Frédéric Jiguet $^{8}$

1-CNRS, Institut des Sciences de l'Evolution, France.

2- Dutch Butterfly Conservation, Wageningen, The Netherlands.

3-Butterfly Conservation, UK.

4-Catalan Ornithological Institute, Spain.

5- Centre Tecnològic Forestal de Catalunya, Spain.

6-British Trust for Ornithology, UK.

7-Finnish Environment Institute, Finland.

8-Conservation des Espèces Restauration et Suivi des Populations-MNHN, France.

9- Department of Biology- Lund University, Lund, Sweden.

10- Institute for Environmental Studies, Charles University in Prague, Czech Republic.

11- Centre for Ecology \& Hydrology, UK.

12-UFZ, Helmholtz, Centre for Environmental Research, Dept.of Community Ecology, Halle, Germany.

13- Museu de Granollers Ciències Naturals, Barcelona, Spain.

14-Statistics Netherlands, The Netherlands.

15-SOVON Dutch Centre for Field Ornithology, The Netherlands.

16-Dept. of Environmental Science and Dept. of Animal Ecology, Institute for Water and Wetland Research, Radboud University Nijmegen, the Netherlands

17-Czech Society for Ornithology, Czech Republic.

18-Lab of Entomology, Wageningen University, Wageningen, The Netherlands.

*Contact information:

Vincent Devictor: vincent.devictor@univ-montp2.fr 
Climate changes have profound effects on the distribution of numerous plant and animal species $^{1-3}$. However, whether and how different taxonomic groups are able to track climate changes at large spatial scale is still unclear. Here, we measure and compare the climatic debt accumulated by bird and butterfly communities at a European scale over two decades (1990-2008). We quantified the yearly change in community composition in response to climate change for 9490 bird and 2130 butterfly communities distributed across Europe ${ }^{4}$. We show that changes in community composition are rapid but different between birds and butterflies and equivalent to a $37 \mathrm{~km}$ and $114 \mathrm{~km}$ northward shift in bird and butterfly communities, respectively. We further found that during the same period, the northward shift in temperature in Europe was even faster so that the climatic debt of birds and butterflies correspond to a $212 \mathrm{~km}$ and $135 \mathrm{~km}$ lag behind climate. Our results indicate both that birds and butterflies do not keep up with temperature increase, and the accumulation of different climatic debts for these groups at national and continental scales.

Species are not equally at risk when facing climate change. Several species-specific attributes have been identified as increasing species' vulnerability to climate change including diets, migratory strategy, main habitat types, and ecological specialization ${ }^{5-7}$. Moreover, while phenotypic plasticity may enable some species to respond rapidly and effectively to climate change ${ }^{8,9}$, others may suffer from the induced spatial mismatch and temporal mistiming with their resources ${ }^{10,11}$. For instance, species such as great tits and flycatchers have been shown to become desynchronized with their main food supply during the nesting season ${ }^{12}$. 
But beyond individual species' fates, climate change should also affect species interactions and the structure of species assemblages within and across different taxonomic groups over large spatial scales ${ }^{13-15}$. For instance, ectotherms should be more directly affected by climate warming and taxonomic groups with short generation time should favor faster evolutionary responses to selective pressures induced by climate changes ${ }^{13}$. Yet, whether different taxonomic groups are tracking climate change at the same rate over large areas is still unclear and methods to routinely assess the mismatch between temperature increases and biodiversity responses at different spatial scales are still missing ${ }^{16}$.

Here, we used extensive monitoring data of birds and butterflies distributed across Europe to assess whether, regardless of their species-specific characteristics, organisms belonging to a given group are responding faster or slower than organisms belonging to another group over large areas. We characterized bird and butterfly communities in 9490 and 2130 sample sites respectively by their community temperature index (CTI) for each year from 1990 to 2008 (Supplementary Fig. 1). The CTI is a simple means to measure the rate of change in community composition in response to temperature change ${ }^{4}$. It was recently adopted as an indicator of climate change impact on biodiversity by the pan-European framework supporting the Convention on Biological Diversity (Streamlining European 2010 Biodiversity Indicators, SEBI).

The CTI reflects the relative composition of high versus low-temperature dwellers in local communities. High versus low-temperature dwellers are first differentiated according to their Species Temperature Index (STI). STI of a given species is simply the 
average temperature of the species range and is taken as a proxy for species' dependency on temperature. CTI is then calculated, for a given monitored site, as the average of species' STI weighted by species abundances (CTI is thus expressed in degrees Celsius). A temporal increase in CTI directly reflects that the species assemblage of the site is increasingly composed of individuals belonging to species dependent on higher temperature (i.e. with high STI).

This approach allows a comparison of the velocity of changes in communities of a given taxonomic group and of temperature. Indeed, the temporal slope of the change in CTI gives the rate of change in community composition in response to climate change through time $\left({ }^{\circ} \mathrm{C} . y e a r^{-1}\right)$. The south-north gradient in CTI $\left({ }^{\circ} \mathrm{C} \cdot \mathrm{km}^{-1}\right)$ then provides an estimate of the rate of change in CTI in kilometers. Providing that this gradient is linear, the temporal change in CTI can be considered as equivalent to a northward shift in CTI using the ratio between the temporal trend and the spatial gradient in CTI $\left({ }^{\circ} \mathrm{C}\right.$.year ${ }^{-}$ $\left.{ }^{1} /{ }^{\circ} \mathrm{C} \cdot \mathrm{km}^{-1}=\mathrm{km} . \mathrm{year}^{-1}\right)$. The same can be done independently for temperature to estimate the velocity of its northward shift $\left(\mathrm{km} \text {.year }{ }^{-1}\right)^{17}$. The comparison between the velocity of CTI with the velocity of temperature then provides an estimate of the lag between the spatial shift in temperature and community response.

Using this approach, we found that from 1990 to 2008, the CTI of European birds (bird CTI) has increased steadily $\left(+2.6 \pm 0.19 \times 10^{-3}\right.$ per year; $F_{1,17}=92.12 ; r^{2}=0.84$; $P<0.0001$; Fig. 1a). Moreover, the CTI spatial gradient is equivalent to a loss of $1.26 \pm$ $0.01 \times 10^{-3}{ }^{\circ} \mathrm{C}$ of bird CTI each km from south to north $\left(F_{1,5099}=4776 ; r^{2}=0.78\right.$, $P<0.0001$; Fig. 2a). The temporal increase in bird CTI is thus equivalent to a $37 \pm 3 \mathrm{~km}$ 
northward shift in the composition of bird communities over the period considered ((2.6 $\left.\mathrm{x} 10^{-3} / 1.26 \times 10^{-3}\right) \times 18$ years).

Using the same approach, we also found that European butterfly communities are increasingly composed of individuals belonging to high-temperature dwelling species (trend in butterfly CTI: $+9.3 \pm 0.5 \times 10^{-3}$ per year; $F_{1,17}=12.6 ; r^{2}=0.42 ; P<0.0001$; Fig.1b). The temporal trend in butterfly CTI is much steeper than the trend in bird CTI (difference between slopes: $6.74 \pm 0.5 \times 10^{-3} ; P<0.01$, ANCOVA). The spatial gradient in butterfly CTI of $1.47 \pm 0.08 \times 10^{-3}{ }^{\circ} \mathrm{C}$ loss of CTI per $\mathrm{km}\left(F_{1,797}=1748 ; r^{2}=0.89\right.$; $P<0.0001$, Fig. 2 b) reveals that the composition of butterfly communities has shifted

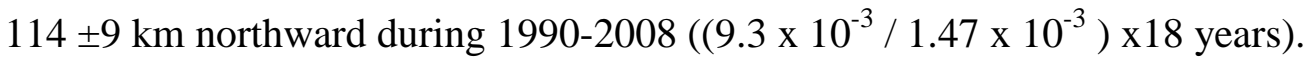

During 1990-2008, the temperature also increased steeply $\left(+5.50 \pm 0.61 \times 10^{-2}{ }^{\circ} \mathrm{C}\right.$ per year, $F_{1,17}=79.6 ; r^{2}=0.81 ; P<0.0001 ;$ Fig. $\left.1 \mathrm{c}\right)$. This temporal trend in temperature can be translated in space using the spatial variation of temperature in Europe ${ }^{17}$. This gradient is equivalent to a loss of $3.98 \pm 0.01 \times 10^{-3}{ }^{\circ} \mathrm{C}$ per $\mathrm{km}$ from south to north $\left(F_{1,30674}=1.7 \mathrm{x}\right.$ $10^{5} ; r^{2}=0.84 ; P<0.00001$, Fig. $\left.2 c\right)$. The temperature increase during 1990-2008 thus corresponds to a northward shift of $249 \pm 27 \mathrm{~km}$ in temperature.

These results indicate that birds and butterflies do not adjust their abundance according to the northward shift of their suitable climates and have accumulated a climatic debt of $212 \mathrm{~km}$ and $135 \mathrm{~km}$ respectively (differences between spatial shift in temperature and in bird CTI and butterfly CTI respectively). 
The change in CTI does not tell which and how particular species are affected by climate change but integrates the actual decline of cold species, increase of warm species, and the combination of both. Therefore, changes in CTI could mostly result from variations in the dominance structure of species occurring locally rather than from real spatial shifts. However, using presence-absence data rather than abundance, we found similar qualitative results (Supplementary Fig. 2). Therefore, the increase in bird and butterfly' CTI also results from changes in the identity of species occurring in local sites rather than only from abundance variations.

Change in CTI could also reflect the strong positive or negative trend of only few species rather than mirror profound changes in community composition. To assess whether our conclusions are robust to the identity of the species considered, we used a systematic re-sampling approach in which the trends in the bird and butterfly CTI were estimated after the random removal of $20 \%$ of the species monitored in each country. This analysis further confirms the robustness of the findings to the change in the species pool considered (Supplementary Fig. 3).

Climatic debt can be defined as an accumulated delay in species' response to change in temperatures attributable to its inability to track climate change. Our results suggest that not only birds and butterflies are not tracking climate change fast enough at large spatial scale, but also that a lag is expanding between the two groups. Climate change has become a strong selective pressure, and response to this pressure is species and contextdependent ${ }^{18}$. What are the consequences of these increasing climatic debts for each group and between groups at large spatial scale remain to be studied. Genetic variability, population size, generation time, but also dispersal or behavioural plasticity all contribute to shape species responses to climate change. In this respect, evolutionary responses to changing climate have already been documented and are particularly 
expected for short-time generation groups such as butterflies ${ }^{19}$. Therefore, significant evolutionary response can, at least to some extent, contribute to the observed trends in CTI.

However, although the data we have do not allow us to disentangle the real lag accumulated by birds and butterflies from possible local adaptation to temperature increase we believe that the rapid adaptations of particular species, if any, are unlikely to produce our results which are based on many species with likely high variability in their evolutionary response. But a close inspection of how changes in CTI vary in space or for particular groups of species (defined according to their localization, dispersal ability, genetic diversity, or any trait of interest suspected to induce differential climatic responses between species and/or groups) could possibly help to disentangle evolutionary from demographic processes in the responses.

The delay in the climatic debt of bird and butterfly communities may disrupt multiple interactions between species. For example, many bird species depend on caterpillars and could therefore suffer from possible modifications of this direct interaction ${ }^{9-12}$. It is also likely that other groups of terrestrial insects on which many insectivorous vertebrates rely are experiencing important northward shifts and changes in community composition. Moreover, birds and butterflies are among the most dispersive species so they should be able to track climate change more easily than other taxonomic groups. Therefore, other multi-group interactions are also probably facing delayed responses to climate change at large scale with unknown consequences for biodiversity and ecosystem functioning ${ }^{1,14,20}$. Finally, the negative consequences of such delays are probably enhanced by interacting and self-reinforcing processes between climate and land-use changes ${ }^{7,21}$.

More rapid responses in butterflies than in birds on average (i.e. calculated at the European level) may be due to butterflies having relatively short life cycles and being 
ectothermic, allowing them to track changes in temperature regimes very closely. These differences may induce higher turnover rates in butterfly communities in response to climate changes $^{22,23}$ which probably contributes to explain the stronger variation in butterfly CTI (Fig. 1b). Therefore, although birds, as a group, are more dispersive than butterflies, our results suggest that they may accumulate higher climatic debt on the long run.

The ability of each taxonomic group to cope with temperature increase (and hence, the potential mismatch between groups) should also depend on the biogeographic, socioeconomic and conservation context. When calculated at the country-level, we found that the temporal trend in CTI was positive and highly significant within nearly every country (Supplementary Table 1). This intra-European analysis also revealed that for a given taxonomic group, the temporal change in CTI was much faster in some countries than in others (Fig. 3). For countries with data available simultaneously for birds and butterflies, we found either a much higher trend in CTI for butterflies or no difference among groups. Overall, these results confirm that the composition of bird and butterfly communities are currently strongly affected by climate change but also reveal that the differences between groups are dependent on the area considered. Interestingly, although the magnitude of the CTI is dependent on the number and identity of the species considered, we showed that the detection of a temporal trend in CTI is very robust to changes in the species considered (Supplementary Fig. 3). Indeed, a given change in CTI only reflects the population adjustments of species according to each species-specific thermal distribution so that, in principle, the trend in CTI should remain sensitive to temperature increase whatever the species considered. However, to be meaningful, the CTI must be based on species representing a gradient in STI values. 
Moreover, the temporal trend in CTI must be calculated on enough sites (and/or years) to avoid confounding factors. Indeed, if the trend in CTI is estimated in a restricted area in which land-use changes have affected a biased sample of species with respect to STIs, the trend could be erroneously interpreted as a community response to climate changes ${ }^{24}$.

Understanding the major ongoing changes in structure and composition of communities within and between trophic levels is necessary to prefigure forecasted changes in ecosystem integrity. Future assessments could quantify whether and how potential delays in the response of different taxonomic groups to climate change vary in different habitats and interact with current trends in land-use changes. We therefore suggest that the approach proposed here can help to improve the traceability of climate change impacts on biodiversity in mapping whether, how, and where, different taxonomic groups are affected by climate changes, using either abundance or presence-absence data, and for national or international-level assessment.

\section{Methods}

We used a method already described to estimate the northward shift in composition of a given taxonomic group ${ }^{4}$ and explained in details in Supplementary information. In brief, the velocity of bird and butterfly communities and of temperature is obtained in two steps. First, for each taxonomic group, we calculated the annual change in the Community Temperature Index reflecting the relative composition of high versus lowtemperature dwellers. The CTI is a simple means to measure the rate of change in community composition in response to temperature change. It is calculated, for a given site, as the average of each Species Temperature Index (STI) occurring in this site, weighted by the species abundances in this site. The STI of a given species is the long- 
term average temperature over the species range (CTI is thereofre expressed in Celsius degree).

A temporal increase in CTI in a given site directly reflects that the relative abundance of individuals belonging to species dependent on higher temperatures (i.e. with a high STI) is increasing in this site. We then estimated the overall temporal slope of the change in the pan-European CTI through time separately for birds and butterflies. This trend was estimated using the change in yearly CTI from 1990 to 2008, calculated in 9490 and 2130 sample sites (located across Europe from Spain to Finland, Supplementary Fig. 1) respectively for birds and butterflies. These schemes were shown to provide high quality data for building pan-European indicators based on trends in population abundance and the dataset used in this study represents the largest dataset ever collated documenting temporal changes in the composition of butterfly and bird communities. The slope of this trend gives an estimate of the rate of change in community composition in response to climate change through time $\left({ }^{\circ} \mathrm{C} . y e a r^{-1}\right)$ for each group ${ }^{4}$. Second, we estimated the south-north gradient in bird and butterfly CTI $\left({ }^{\circ} \mathrm{C} \cdot \mathrm{km}^{-1}\right)$. Because the CTI is linearly decreasing along a south-north gradient, the temporal change in CTI can be considered as equivalent to a northward shift in CTI using the ratio between the temporal trend and the spatial gradient in $\mathrm{CTI}\left({ }^{\circ} \mathrm{C} \cdot \mathrm{year}{ }^{-1} /{ }^{\circ} \mathrm{C} \cdot \mathrm{km}^{-1}=\right.$ $\mathrm{km}_{\text {.year }}{ }^{-1}$ ). The same was done independently for temperature to estimate the velocity of northward shift in temperature $\left(\mathrm{km}\right.$. year $\left.^{-1}\right)$.

\section{References}

1-Parmesan, C. Ecological and Evolutionary Responses to Recent Climate Change. Ann. Rev. Ecol. Evol. Syst. 37, 637-669 (2006).

2-Thomas, C. D., Franco, A. M. A. \& Hill, J. K. Range retractions and extinction in the face of climate warming. Trends Ecol. Evol 21, 415-416 (2006). 
3-Lenoir, J., Gégout, J. C., Marquet, P. A., de Ruffray, P. \& Brisse, H. A. Significant upward shift in plant species optimum elevation during the 20th century. Science 320, $1768(2008)$.

4-Devictor, V., Julliard, R., Jiguet, F. \& Couvet, D. Birds are tracking climate warming, but not fast enough. Proc. R. Soc. B 275, 2743-2748 (2008).

5-Jiguet, F., et al. Climate envelope, life history traits and the resilience of birds facing global change. Global Change Biol. 13, 1672-1684 (2007).

6-Heikkinen, R. K. et al. Assessing the vulnerability of European butterflies to climate change using multiple criteria. Biodivers. Conserv. 3, 695-703 (2010).

7-Warren, M. S. et al. Rapid responses of British butterflies to opposing forces of climate and habitat change. Nature 414, 65-69 (2001).

8-Visser, M. E. Keeping up with a warming world; assessing the rate of adaptation to climate change. Proc. R. Soc. B 275, 649-659 (2008).

9-Charmantier, A. et al. Adaptive phenotypic plasticity in response to climate change in a wild bird population. Science 320, 800-803 (2008).

10-Parmesan, C. Influences of species, latitudes and methodologies on estimates of phenological response to global warming. Glob. Change Biol. 13, 1860-1872 (2007). 11-Sherry, R. A. et al. Divergence of reproductive phenology under climate warming. Proc. Natl Acad. Sci. USA 104, 198-202 (2007).

12-Visser, M. E., Vannoordwijk, A. J., Tinbergen, J. M., and Lessells, C. M. Warmer springs lead to mistimed reproduction in Great Tits (Parus major). Proc. R. Soc. Lond. Ser. B 265, 1867-1870 (1998). 
13-Schweiger, O., Settele, J., Kudrna, O., Klotz, S. \& Kühn, I. Climate change can cause spatial mismatch of trophically interacting species. Ecology 89, 3472-3479 (2008).

14-Harrington, R., Woiwod, I. \& Sparks, T. Climate change and trophic interactions. Trends Ecol. Evol. 14, 146-150 (1999).

15-Pounds, J. A., et al. Widespread amphibian extinctions from epidemic disease driven by global warming. Nature 439, 161-167 (2006).

16-Root, T. L., Price, J. T. \& Hall, K. R. Fingerprints of global warming on wild animals and plants. Nature 421, 57-60 (2003).

17-Loarie, S. R. et al. The velocity of climate change. Nature 462, 24-31 (2009).

18- Hoffmann, A.A. \& Sgrò, C.M. Climate change and evolutionary adaptation. Nature $470479-485$ (2011).

19-Skelly, D.K. et al. Evolutionary responses to climate change. Cons. Biol. 21, 13531355 (2007).

20-Memmott, J. Craze, P. G., Waser, N. M. \& Price, M. V. Global warming and the disruption of plant-pollinator interactions. Ecol. Lett. 10, 710-717 (2007).

21-Brook, B. W., Sodhi, N. S. \& Bradshaw, C. J. A. Synergies among extinction drivers under global change. Trends Ecol. Evol. 23, 453-460 (2008).

22-Kuussaari, M. et al. Extinction debt: a challenge for biodiversity conservation, Trends Ecol. Evol. 24, 564-571 (2009).

23-Thomas, C.D. et al. Extinction risk from climate change. Nature 427, 145-148 (2004).

24- Clavero, M., Villero, D. \& Brotons, L. Climate change or landuse dynamics: do we know what climate change indicators indicate? PLOS ONE 6(4), e18581 (2011). 
Correspondence and requests for materials should be addressed to Vincent Devictor (vincent.devictor@univ-montp2.fr)

\section{Acknowledgements}

We thank all skilled volunteer bird- and butterfly-watchers involved in national monitoring programs: altogether, we estimated that more than 1,500,000 man-hours have been spent to conduct the bird and butterfly monitoring surveys (this estimate only corresponds to field work) necessary to this study. We thank Prof. Chris D. Thomas for his comments on the manuscript and two referees for their constructive suggestions. We thank...

\section{Author contributions}

VD performed all statistical analysis and wrote the paper. VD CS and FJ designed the general study. All other authors equally contributed to data collection, formulations of theoretical expectations, writing and revision of the paper. 


\section{Figure legends}

Fig. 1. Temporal trend of CTI and temperature in Europe from 1990 to 2008 ( \pm standart error of the mean in dashed line). (a) for the bird communities monitored in Europe from 1990 to 2008, (b) of CTI for butterfly communities and (c) for March-September temperature. Temperature anomalies are calculated as the departure from the average of the base period 1961-1990.

Fig. 2. Spatial trend of CTI and temperature in Europe. (a), for the bird communities, (b) for butterfly communities. Each point represents the CTI for a given sample site monitored in 2005. (c) Spatial temperature gradient. Temperature is the average of March-September temperature to match the breeding season of birds and butterflies. Distance ( $\mathrm{X}$ axis) is calculated from the southern border of the studied area.

Fig. 3. European variations in the temporal trend of bird and butterfly CTI. The map shows the temporal trend of bird and butterfly CTI for each country. The height of a given arrow is proportional to the temporal trend and its direction corresponds to the sign of the slope (from south to north for positive slopes). The arrow is opaque if the trend is significant. 
Fig. 1. Temporal trend of CTI and temperature in Europe from 1990 to 2008 ( \pm standart error of the mean in dashed line). (a) for the bird communities monitored in Europe from 1990 to 2008, (b) of CTI for butterfly communities and (c) for March-September temperature. Temperature anomalies are calculated as the departure from the average of the base period 1961-1990. 


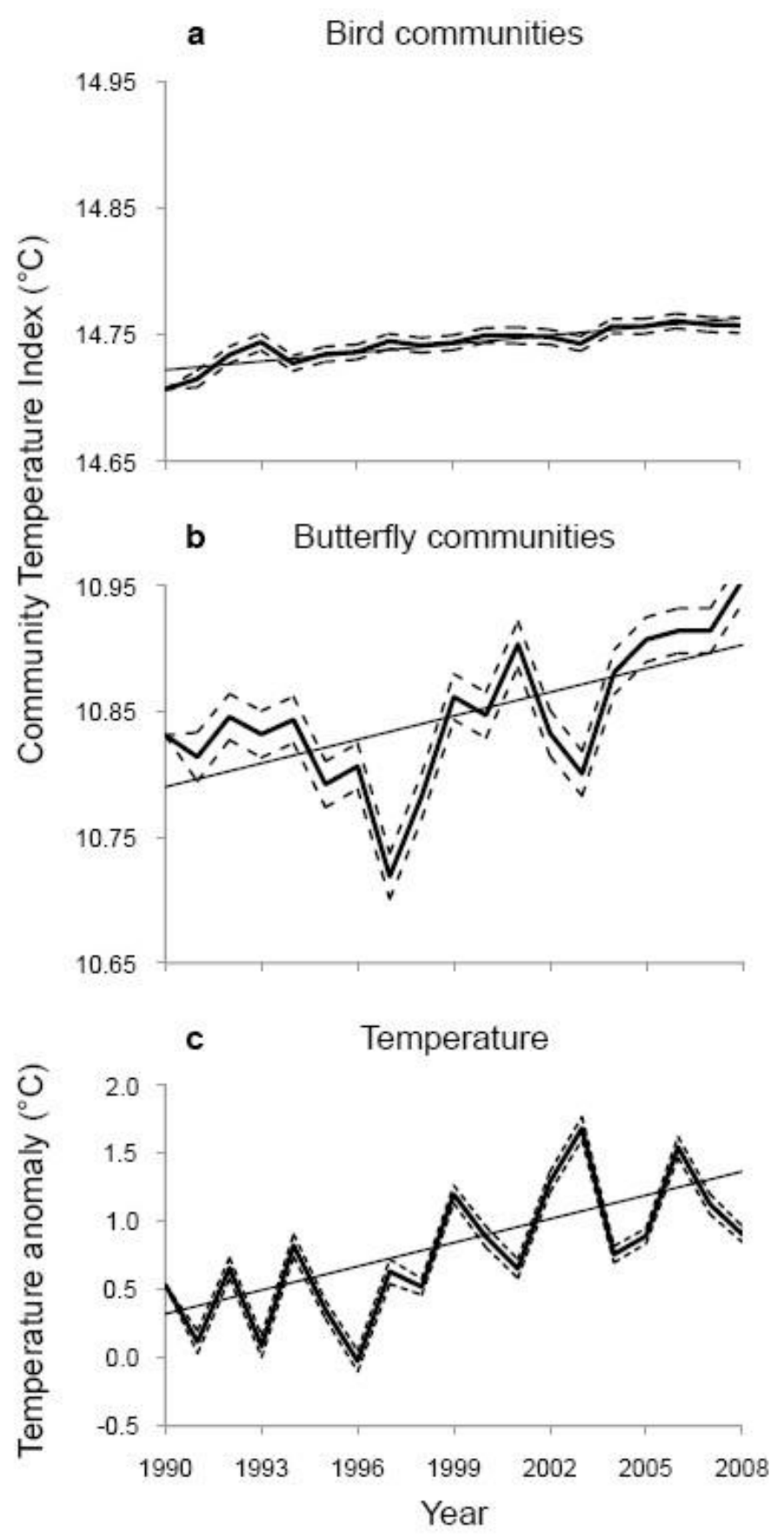



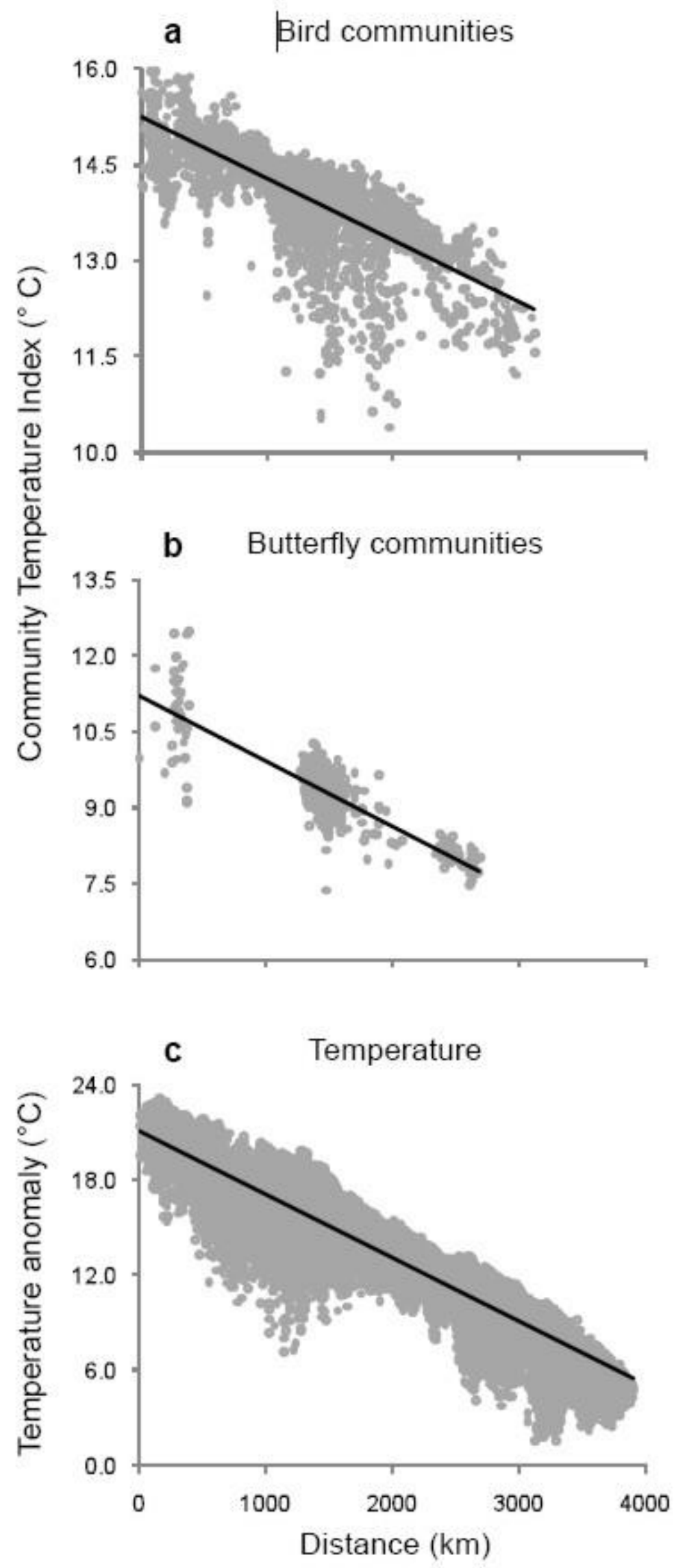
Fig. 3 European variations in the temporal trend of bird and butterfly CTI. The map shows the temporal trend of bird and butterfly CTI for each country. The height of a given arrow is proportional to the temporal trend and its direction corresponds to the sign of the slope (from south to north for positive slopes). The arrow is opaque if the trend is significant.

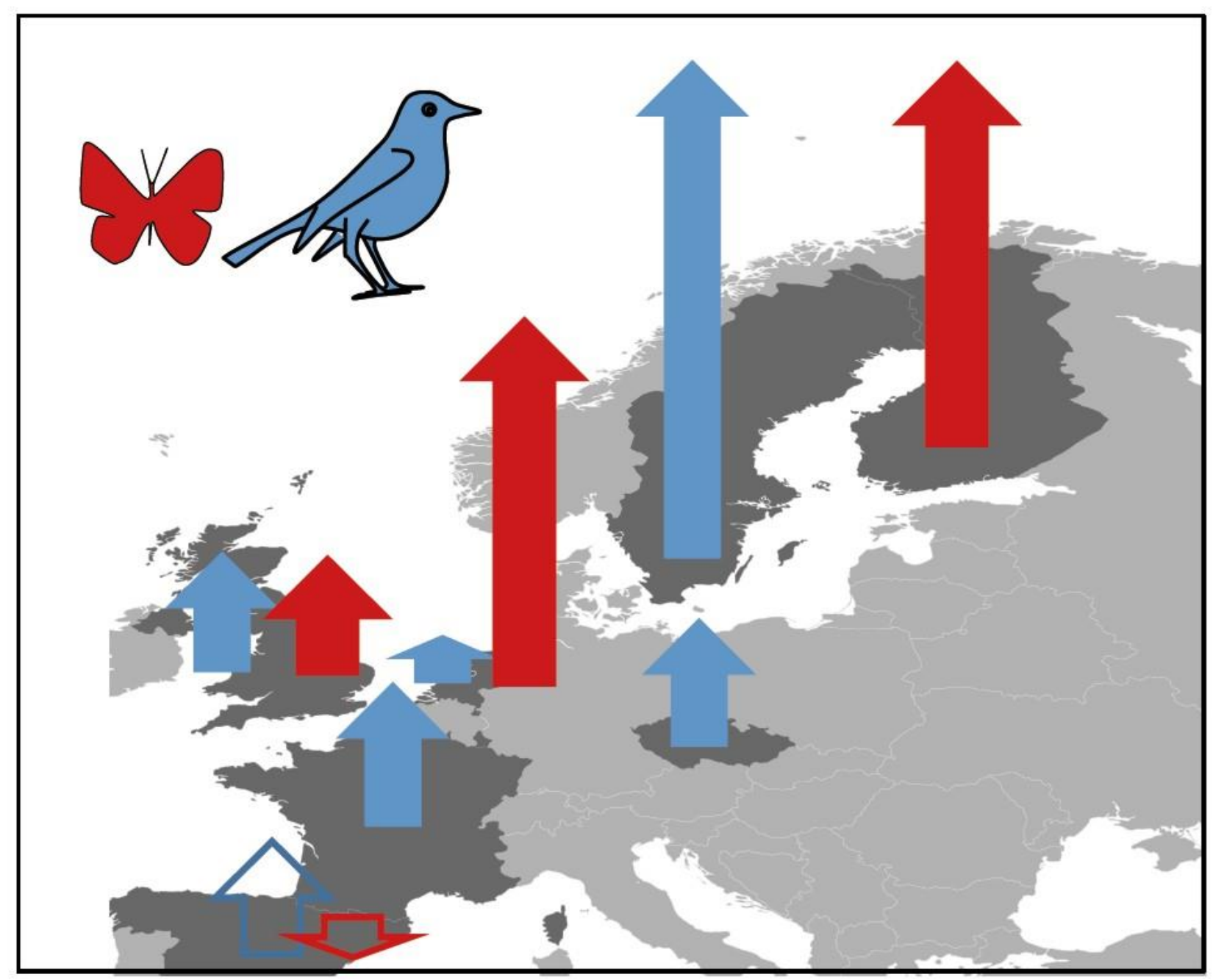

